\title{
Endogenous activation of metabotropic glutamate receptors supports the proliferation and survival of neural progenitor cells
}

\author{
V Di Giorgi-Gerevini ${ }^{\star, 1,5}$, D Melchiorri ${ }^{1,5}$, G Battaglia ${ }^{2}$, \\ L Ricci-Vitiani ${ }^{3}$, C Ciceroni ${ }^{1}$, CL Busceti ${ }^{2}$, F Biagioni ${ }^{2}$, \\ L lacovelli ${ }^{1,2}$, AM Canudas ${ }^{1}$, E Parati ${ }^{4}$, R De Maria ${ }^{3}$ and F Nicoletti ${ }^{1,2}$ \\ ${ }^{1}$ Department of Human Physiology and Pharmacology, University of Rome, \\ La Sapienza, Italy \\ 2 INM Neuromed, Pozzilli, Italy \\ ${ }^{3}$ Istituto Superiore di Sanità, Rome, Italy \\ ${ }^{4}$ Istituto Neurologico Carlo Besta, Milan, Italy \\ 5 These authors contributed equally to this work \\ * Corresponding author: V Di Giorgi Gerevini, Department of Human Physiology \\ and Pharmacology, University of Rome, La Sapienza, Piazzale Aldo Moro 5 , \\ 00185 Roma, Italy. Tel: + 3906 49912969; Fax: + 3906 4450307; \\ E-mail: valeriadigiorgi@ hotmail.com
}

Received 23.6.04; revised 21.2.05; accepted 10.3.05; published online 10.6.05 Edited by RA Knight

\begin{abstract}
The use of neural progenitor cells (NPCs) is limited by the incomplete knowledge of the extracellular signals regulating their proliferation and survival. We report that cultured mouse NPCs express functional mGlu3 and mGlu5 metabotropic glutamate receptors. Pharmacological blockade of both receptors reduced NPC proliferation and survival, whereas activation of mGlu5 receptors substantially enhanced cell proliferation. Adult mice lacking mGlu5 receptors or treated with mGlu5 or mGlu3 receptor antagonists showed a dramatic reduction in the number of dividing neuroprogenitors present in the subventricular zone and in the dentate gyrus of the hippocampus. These data disclose a novel function of mGlu receptors and offer new potential strategies for the optimization of cell replacement therapy in neurodegenerative disorders.

Cell Death and Differentiation (2005) 12, 1124-1133.

doi:10.1038/sj.cdd.4401639; published online 10 June 2005
\end{abstract}

Keywords: metabotropic glutamate receptors; neural progenitor cells; cell proliferation; subventricular zone; mGlu5 knockout mice

\footnotetext{
Abbreviations: NPC, neuroprogenitor cells; mGlu, metabotropic glutamate receptors; CNS, central nervous system; EGF, epidermal growth factor; bFGF, basic Fibroblast Growth Factor; GFAP, glial fibrillar acidic protein; Tuj1, beta III tubulin (clone J1); GalC, galactocerebroside; NBQX, 1,2,3,4-tetrahydro6-nitro-2, 3-dioxo-benzo[f]quinoxaline-7-sulfonamide; PI, polyphosphoinositide; MPEP, 2-methyl-6-(phenylethynyl) pyridine; MAPK, mitogen-activated protein kinase; DHPG, 3,5-dihydroxyphenylglycine; PI-3-K, phosphatidylinositol-3-kinase; BrdU, bromodeoxyuridine; DG, dentate gyrus; SVZ, subventricular zone; cAMP, cyclic AMP
}

\section{Introduction}

Neuroprogenitor cells (NPCs, variously referred to as neural progenitor cells or multipotent neural precursors) comprise a relatively undifferentiated population of cells capable of giving rise to neurons and glia of the central nervous system (CNS) ${ }^{1-4}$ These cells are present in the developing and adult CNS, and can be isolated and expanded in vitro using mitogenic factors, such as epidermal growth factor (EGF) and basic fibroblast growth factor (bFGF) ${ }^{5}$ However, growth factors are not ideal candidates as drugs of support in protocols of cell replacement therapy because of their limited central bioavailability. Little is known on how G-proteincoupled receptors affect the physiology of NPCs, although these receptors are targeted by a large number of drugs. Here, we focus on metabotropic glutamate (mGlu) receptors, which are implicated in the regulation of developmental plasticity. ${ }^{6-16}$ mGlu receptors form a family of eight subtypes, of which mGlu1 and mGlu5 are coupled to polyphosphoinositide $(\mathrm{PI})$ hydrolysis, whereas all other subtypes are negatively coupled to adenylyl cyclase in heterologous expression systems. ${ }^{17,18}$ Although mGlu receptors regulate synaptic transmission, some of the subtypes (particularly, the mGlu5 receptor) are expressed at developmental stages that precede synaptic formation and are also found in nonneuronal tissues. ${ }^{19-21} \mathrm{~A}$ specific role for mGlu5 receptors in developmental plasticity is suggested by numerous observations. For example, endogenous activation of mGlu5 receptors in immature cortical neurons generates calcium oscillations, ${ }^{12}$ and homozygous null mutations of either mGlu5 receptors or phospholipase C- $\beta 1$ disrupt the cytoarchitectural differentiation of 'barrels' in the mouse somatosensory cortex. ${ }^{13}$ Endogenous activation of mGlu5 receptors is also required for the maturation and survival of cultured cerebellar granule cells. ${ }^{16,22}$ Whether mGlu5 receptors or other mGlu receptor subtypes are involved in the regulation of NPCs in the CNS is unknown. We now report that two mGlu receptor subtypes, that is mGlu3 and mGlu5, are expressed by NPCs, and that endogenous activation of mGlu5 receptors in particular controls the proliferation and/or survival of NPCs both in vitro and in vivo.

\section{Results}

Metabotropic glutamate receptor subtypes 3 and 5 are expressed by cultured NPCs

Cultured NPCs aggregated to form neurospheres. These cells, when grown in serum-free medium containing EGF and bFGF, were able to proliferate even after cryopreservation. Over $95 \%$ of cells were immunopositive for nestin, with a small percentage of cells (less than $3 \%$ ) expressing astroglial (glial fibribrillar acidic protein (GFAP)) or neuronal (beta III tubulin 
(clone J1) (Tuj1)) markers (Figure 1). None of the nestin ${ }^{+}$ cells was positive for TuJ1 and less than $0.5 \%$ of cells coexpressed GFAP. When plated in the absence of mitogens, NPCs differentiated into astrocytes, neurons or oligodendrocytes as assessed by immunostaining for GFAP, Tuj1 and galactocerebroside (GalC), respectively (Figure 1b, c, d). NPC cultures at 4-6 passages grown under proliferating conditions expressed mGlu3, mGlu4, mGlu5 and mGlu7 receptor mRNA, whereas only mGlu3 and mGlu5 receptor mRNA was detected at later passages (Figure 2a). Expression of mGlu3 and mGlu5 receptor proteins is shown in Figure $2 \mathrm{~b}$. The density of both receptors was greater in cultures at $>10$ passages. For this reason, we have performed most of the experiments in cultures at 12-14 passages. In these cultures, activation of mGlu5 receptors with the selective agonist quisqualate (applied in combination with the AMPA receptor antagonist 1,2,3,4-tetrahydro6nitro-2,3-dioxo-benzo[f]quinoxaline-7-sulfonamide (NBQX) stimulated $\mathrm{PI}$ hydrolysis (Figure $2 \mathrm{c}$ ), that is the classical transduction pathway associated with mGlu5 receptors.
Stimulation by quisqualate was abolished by the mGlu5 receptor antagonist 2-methyl-6-(phenylethynyl)pyridine (MPEP) (Figure 2c). MPEP is a selective noncompetitive antagonist of mGlu5 receptors and therefore, by definition, can block mGlu5 receptors independently of the concentrations of ambient glutamate. ${ }^{23}$ In addition, MPEP inhibits the constitutive activity of mGlu5 receptors (i.e. receptor activity in the absence of any ligand), behaving as an inverse agonist. ${ }^{24}$ Addition of quisqualate + NBQX also activated the mitogenactivated protein kinase (MAPK) pathway (Figure 2e). The action of quisqualate was mimicked by the selective mGlu1/5 receptor agonist 3,5-dihydroxyphenylglycine (DHPG, $100 \mu \mathrm{M}$ ), which, however, was less efficacious in stimulating PI hydrolysis and the MAPK pathway (not shown). We could not detect any stimulation of the phosphatidylinositol-3-kinase (PI-3-K) pathway by either quisqualate or DHPG because the background levels of phosphorylated Akt were too high even after $4 \mathrm{~h}$ of withdrawal from EGF and bFGF (not shown). mGlu3 receptors expressed by cultured NPCs were also functional, as shown by the ability of the
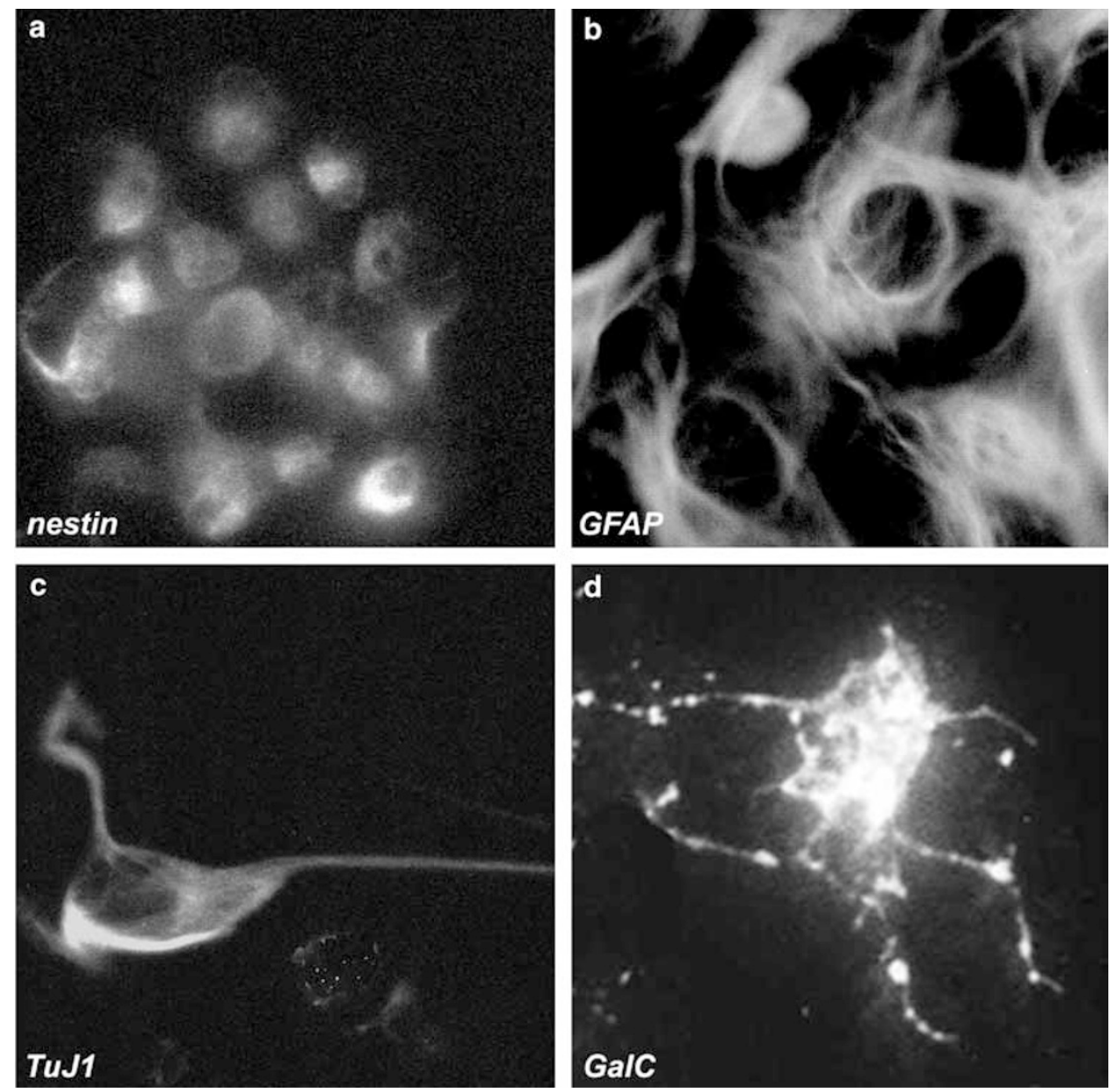

Figure 1 Immunohistochemical characterization of cultured NPCs grown under 'proliferating' conditions or committed to differentiate by the removal of mitogens and addition of $5 \%$ fetal calf serum. Nestin immunostaining NPCs aggregating into neurospheres under proliferating conditions (i.e. in serum-free medium containing EGF and bFGF) is shown in (a). GFAP, TuJ1 and GalC immunostaining in cultured NPCs differentiating in serum-containing medium is shown in (b), (c) and (d), respectively. Objectives: $10 \times$ in (a) and $40 \times$ in (b-d) 


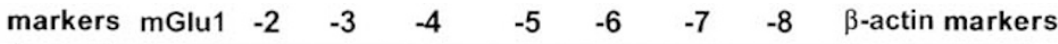

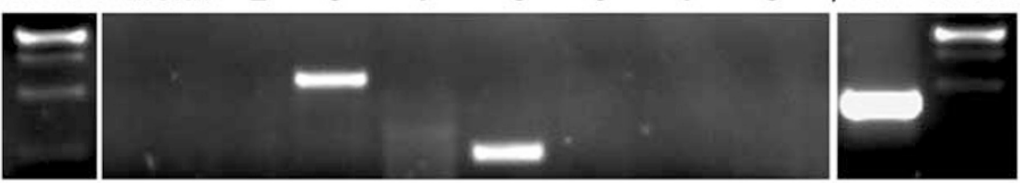

b

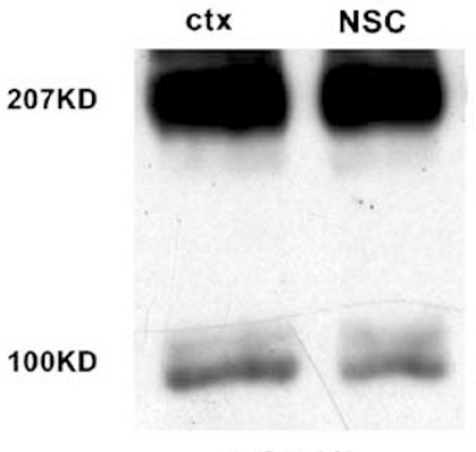

mGlu2/3

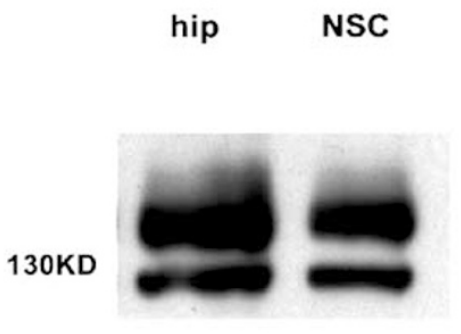

mGlu5

C
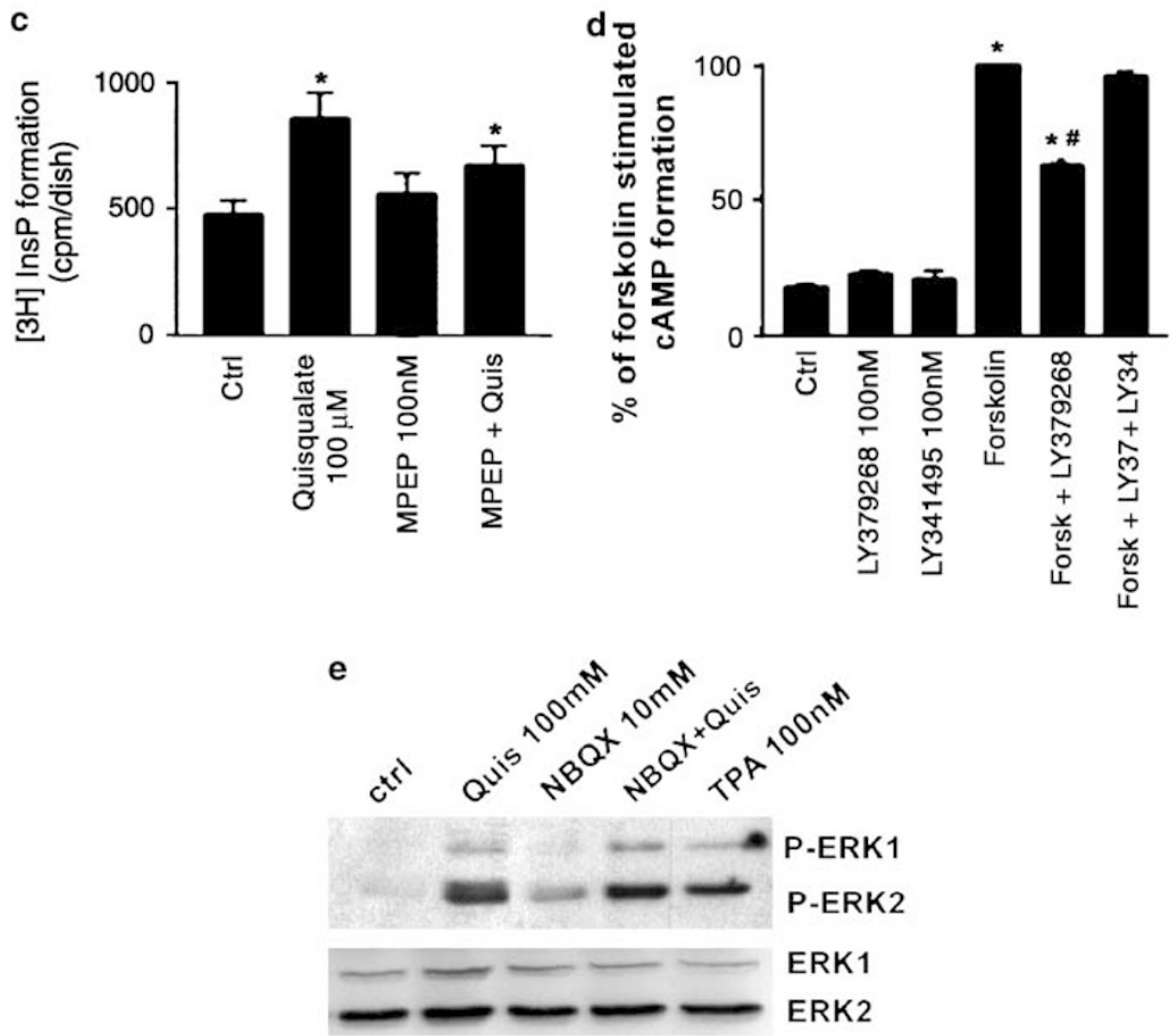

Figure 2 Cultured NPCs express mGlu3 and mGlu5 metabotropic glutamate receptors. (a) RT-PCR products for the eight known mGlu receptor subtypes; the single amplification product for $\beta$-actin shows no contamination by genomic DNA (see Materials and Methods). (b) Western blot of mGlu3 and mGlu5 receptor proteins. Both monomeric and dimeric mGlu2/3 receptors are shown at 100 and $207 \mathrm{kDa}$; the upper of the two bands of mGlu5 receptors corresponds to the receptor monomer because it is absent in tissue from mGlu5 knockout mice (not shown); ctx=adult mouse cerebral cortex; hip = adult mouse hippocampus. (c) Stimulation of PI hydrolysis by the mGlu $1 / 5$ receptor agonist quisqualate (Quis) in the absence or presence of MPEP. (d) Inhibition of forskolin (Forsk)-stimulated cAMP formation by the mGlu2/3 receptor agonist LY379268. Note that the action of LY379268 is prevented by the mGlu2/3 receptor antagonist LY341495. LY341495 did not affect per se forskolin-stimulated cAMP formation. (e) Assessment of the MAPK pathway in cultures treated with quisqualate + NBQX. Stimulation of the pathway by the phorbo ester, TPA, is also shown. The immunoblot was repeated twice with identical results. In (c) and (d), values are means \pm S.E.M. of six individual determinations. ${ }^{*} P<0.05$ versus controls (Ctr); ${ }^{\#} P<0.05$ versus quisqualate alone (c) or versus both forskolin and forskolin combined with LY379268 and LY341495 (d) (one-way ANOVA + Dunnett's $t$-test)

selective agonist (-)-2-oxa-4-aminobicyclo[3.1.0]hexane-4, 6-dicarboxylic acid (LY379268) to reduce forskolin-stimulated cyclic AMP (cAMP) formation (Figure 2d). Inhibition of cAMP formation by LY379268 was prevented by the mGlu2/3 receptor antagonist 2S-2-amino-2-(1S,2S-2-carboxycyclopropan-1-yl)-3-(xanth-9-yl)propionate (LY341495) (Figure 2d). 


\section{Activation of mGlu3 and mGlu5 receptors regulates NPC proliferation and survival}

During the first 4 days in vitro (DIV), the steady-state concentrations of extracellular glutamate levels ranged from $0.5 \pm 0.06 \mu \mathrm{M}$ at $1 \mathrm{DIV}$ to $1.8 \pm 0.3 \mu \mathrm{M}$ at $4 \mathrm{DIV} \quad(n=4)$. Because these concentrations are sufficient to endogenously activate mGlu receptors, we first used subtype-selective antagonists to unravel a role for mGlu receptors in the regulation of cell proliferation and survival. Cultures were treated daily for 3 days with the mGlu5 receptor antagonist MPEP $(100 \mathrm{nM})$, or with the mGlu2/3 receptor antagonist LY341495 (100 nM or $3 \mu \mathrm{M})$. At $3 \mu \mathrm{M}$, LY341495 loses its selectivity, and behaves as a pan-mGlu receptor antagonist. ${ }^{25}$ Treatment of NPCs at 12 passages with the antagonists reduced cell proliferation, as indicated by a lower percentage of cells entering the G2/M phase of the cell cycle (Figure 3a) and by a reduction in cyclin D, cyclin A2 and cyclin B1 mRNA levels (Figure $3 b$ ). This effect was associated with an increase in the spontaneous death of cultured NPCs, as shown by a greater percentage of cells harboring hypoploid DNA (Figure 4a) and by increases in LDH release (Figure $4 \mathrm{~b}$ ) and caspase-3 activity (Figure 4c), suggesting that a percentage of NPCs died by apoptosis followed by secondary necrosis. The combined effects of mGlu receptor antagonists on cell proliferation and survival were confirmed by the microscopic analysis of neurosphere diameters, which progressively increased with time in culture. During the 4 days of treatment, we measured the neurosphere diameters every day in comparable fields for each dish. Treatment of NPCs with MPEP or LY341495 reduced the percentage of neurospheres with large diameters since the first day of exposure. Cultures treated with MPEP or high concentrations of LY341495 (which inhibit mGlu3, mGlu5 and other mGlu receptor subtypes)

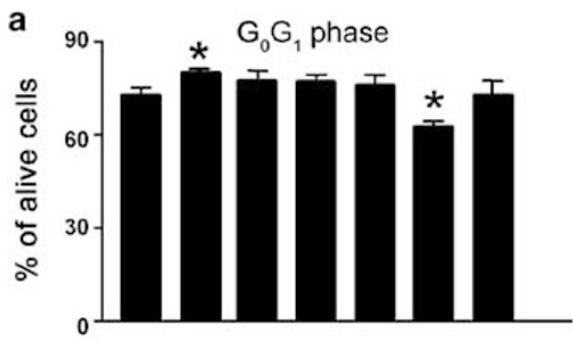

b
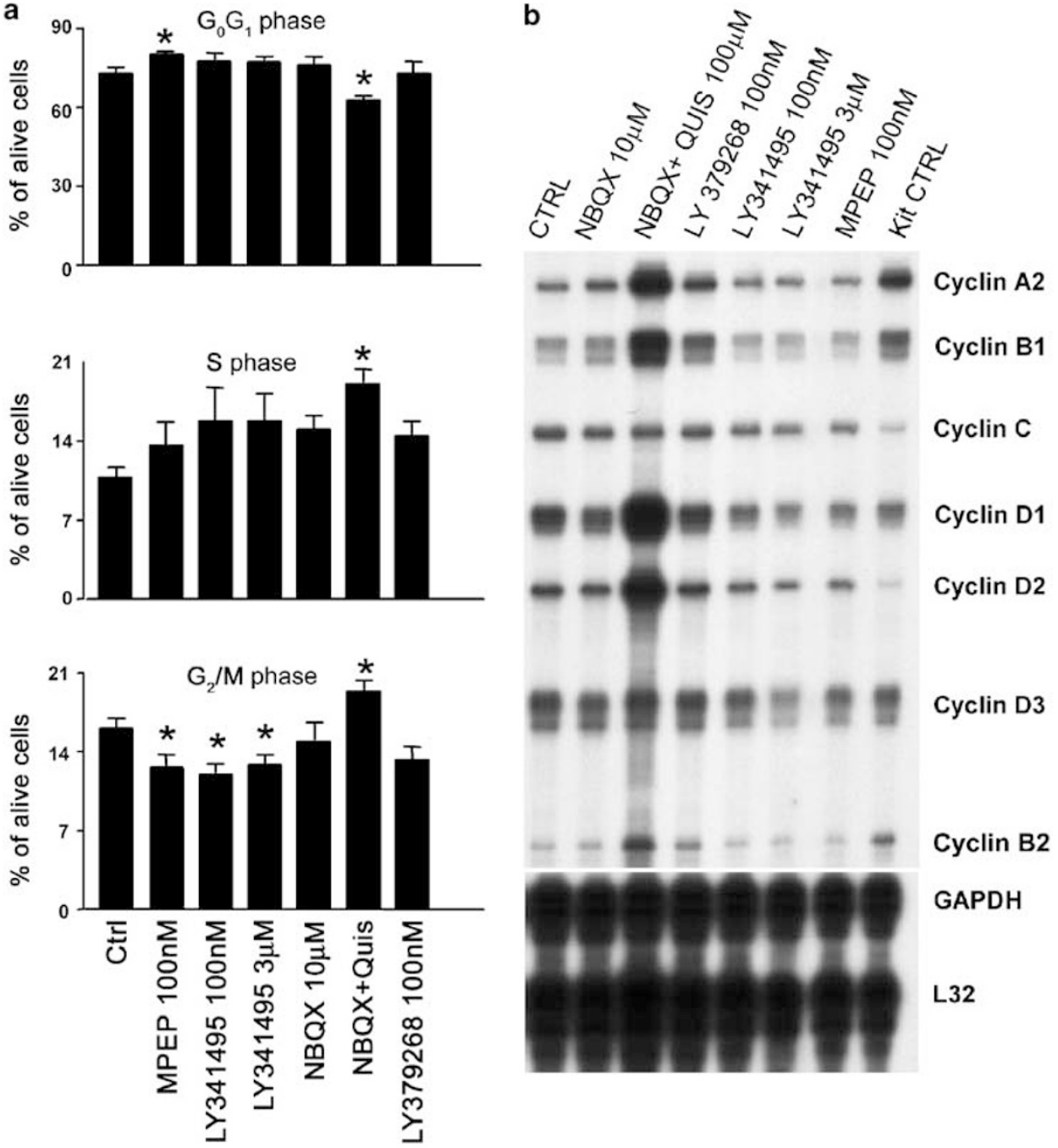

Figure 3 Activation of mGlu5 receptors supports the proliferation of cultured NPCs. (a) FACS analysis of cell cycle in cultured NPCs exposed for 3 days to mGlu receptor agonists or antagonists (each drug being applied daily since the time of plating). Values are means \pm S.E.M. of nine determinations from three separate experiments. ${ }^{*} P<0.05$ versus controls (Ctrl) (one-way ANOVA + Dunnett's $t$-test). (b) RPA analysis of cyclin mRNA levels after a 3-day exposure to mGlu receptor agonists or antagonists (see above). Two housekeeping genes (GAPDH and L32) are also shown. Extracts from three pooled cultured dishes are loaded per lane. The experiment was repeated two times with identical results 


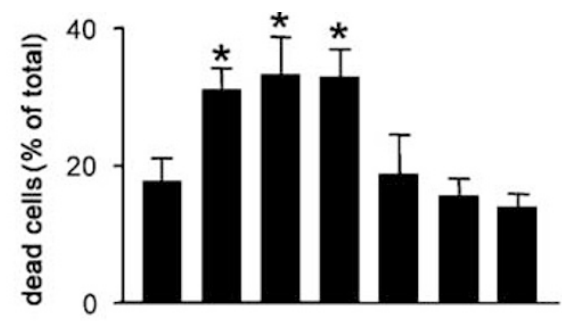

b
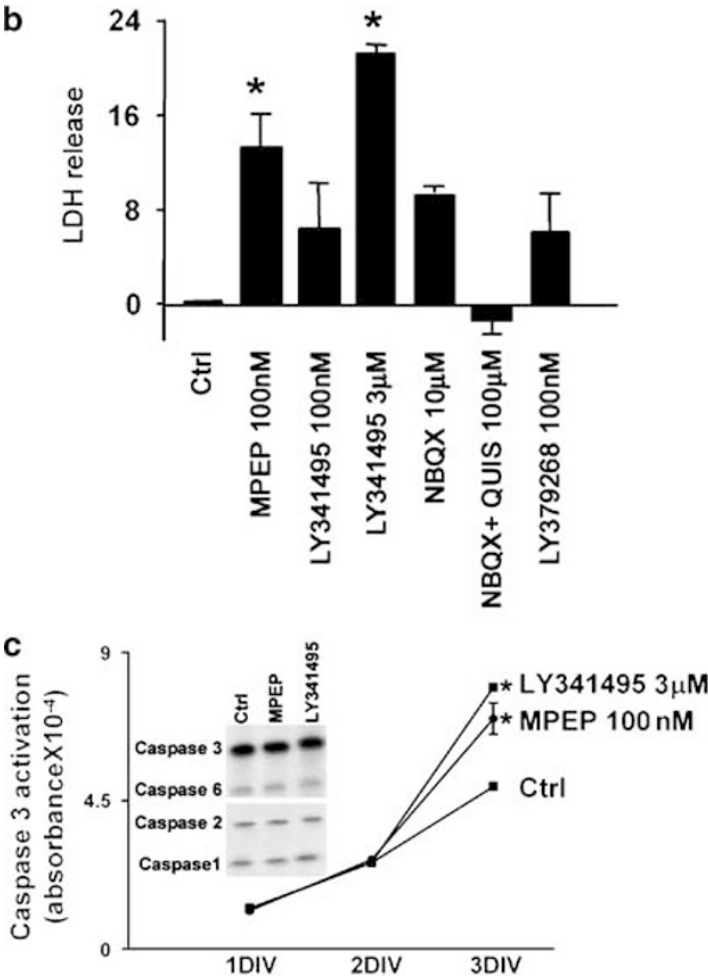

Figure 4 Pharmacological blockade of mGlu receptors reduces NPC survival in culture. FACS analysis of cells with hypoploid DNA (a), and measurements of LDH release (b) or caspase-3 activity (c) after a 3-day treatment with mGlu receptor agonists or antagonists; values are means \pm S.E.M. of nine determinations from three separate experiments in (a) and (b), and six determinations from two separate experiments in (c); ${ }^{*} P<0.05$ versus controls (Ctrl) (one-way ANOVA + Dunnett's $t$-test). The inset in (c) shows that treatments with MPEP or LY341495 did not change caspase mRNA levels as assessed by RPA

showed a multimodal distribution of neurosphere diameters (Figure 5). Cell proliferation was also assessed using a quantitative proliferation assay that is based on the conversion of 3-(4,5-dimethylthiazol-2-yl)-5-(3-carboxymethoxyphenyl)-2-(4-sulfophenyl)-2H-tetrazolium inner salt (MTS) into formazan (see Materials and Methods). Using this assay, we have extended the study to NPC cultures at four passages and to cultures obtained from mGlu5 receptor knockout mice. The two antagonists that we have tested (i.e. MPEP and LY341495 at low and high concentrations) reduced cell proliferation rate in cultures at four and 12 passages from wild-type mice (results of cultures at four passages are shown in Figure 6). LY341495 was more effective at $3 \mu \mathrm{M}$ (when it loses its selectivity for mGlu2/3 receptors) than at $100 \mathrm{nM}$, suggesting that blockade of both mGlu2/3 and mGlu5 receptors contributes to reduce cell proliferation. NPC cultures from mGlu5 knockout mice (tested only at four passages) showed a lower proliferation as compared to cultures from wild-type mice (Figure 6). Cultures from knockout mice were not responsive to the antiproliferative action of MPEP, whereas they were still responsive to LY341495, but without difference between low and high concentrations of the drug (Figure 6).

We also examined whether pharmacological agonists of mGlu3 or mGlu5 receptors could affect cell proliferation and survival despite the presence of the endogenous agonist (i.e. glutamate) in the medium. Cultures treated with quisqualate + NBQX for 3 days had a greater percentage of cycling cells (Figure 3a), showed a dramatic rise in the transcripts of most of the cyclins involved in the regulation of cell cycle (particularly cyclin A2, B1, D1 and D2) (Figure 3b) and showed an increased percentage of neurospheres with large diameters (Figure 5). Pharmacological activation of mGlu5 receptors had no discernible effect on the spontaneous death of NPCs in culture (see Figure $4 \mathrm{a}$ and b). DHPG $(100 \mu \mathrm{M})$ mimicked the action of quisqualate $+\mathrm{NBQX}$ (not shown). Treatment with the potent mGlu2/3 receptor agonist LY379268 (100 nM) produced no discernible changes in the distribution of cell cycle phases (Figure $3 a$ ) in spite of a small rise in cyclin A2 and cyclin B1 mRNA levels (Figure 3b). A 3day treatment of cultures with LY379268 increased the percentage of neurospheres with large diameters similarly to that observed with quisqualate + NBQX (Figure 5). LY379268 had no apparent effects on NPC survival in culture (Figure 4a).

\section{mGlu5 receptor blockade reduces the number of progenitor cells in zones of active neurogenesis of the adult mouse forebrain}

To examine whether mGlu receptors could also control the proliferation rate of NPCs in their native environment, we treated adult mice with bromodeoxyuridine (BrdU) $(50 \mathrm{mg} / \mathrm{kg}$, i.p., injected 2 times/day for 4 days) and counted the number of proliferating cells in two zones of active neurogenesis: the dentate gyrus (DG) of the hippocampus and the subventricular zone (SVZ). The following groups of mice were examined: wild-type mice; mGlu5 knockout mice; wild-type mice implanted subcutaneously with an osmotic minipump containing saline; and mice implanted with minipumps releasing for 7 days MPEP, LY379268, LY341495 or LY379268 + LY341495 (all at $1 \mathrm{mg} / \mathrm{kg} /$ day). All these drugs are centrally bioavailable. We could not inject quisqualate or DHPG intracerebroventricularly because both drugs are known to induce motor seizures. BrdU ${ }^{+}$cells were counted in comparable microscopic sections by an observer who was unaware of the treatments. Interestingly, all mGlu5-/- mice showed a much smaller ventricular cavity (compare Figure $7 f$ with Figure 7e and g) apparently due to hyperplasia of the choroid plexus. The number of $\mathrm{BrdU}^{+}$cells was much smaller in the DG and SVZ of mGlu5-/- mice as compared with control mice (Figure $7 \mathrm{~b}$ and $\mathrm{f}$, and see graphs in Figure $7 \mathrm{~d}$ and h). Continuous peripheral infusion of MPEP also reduced the number of proliferating cells in both regions (Figure $7 \mathrm{c}, \mathrm{d}, \mathrm{g}$ and $\mathrm{h}$ ), indicating that endogenous activation of mGlu5 

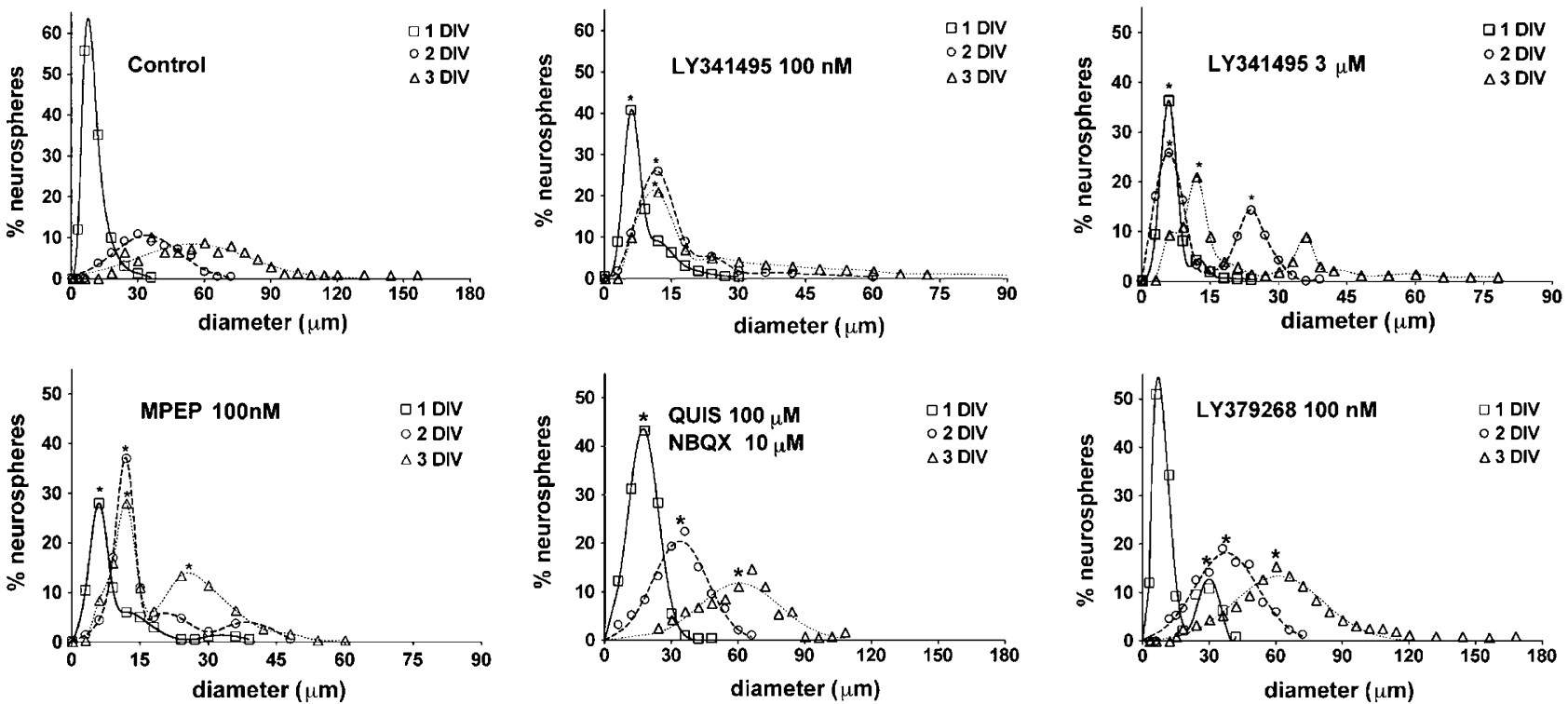

Figure 5 Pharmacological modulation of mGlu3 and mGlu5 receptors affects the diameter of neurospheres in cultured NPCs grown under proliferating conditions. The distribution of neurospheres by their diameter is shown after 1-3 days of exposure to MPEP, LY341495, quisqualate + NBQX or LY379268. Each drug was applied daily starting from the time of plating. Each value represents the mean of three determinations. S.D. was always less than $10 \%$ of the mean value. ${ }^{\star} P<0.05$ (two-way ANOVA + Bonferroni's t-test) versus the respective controls. Note that antagonists (MPEP, LY341495) decreased the diameters of neurospheres, whereas an opposite effect was induced by agonists (quisqualate + NBQX or LY379268). NBQX alone did not affect the diameter of neurospheres (not shown)

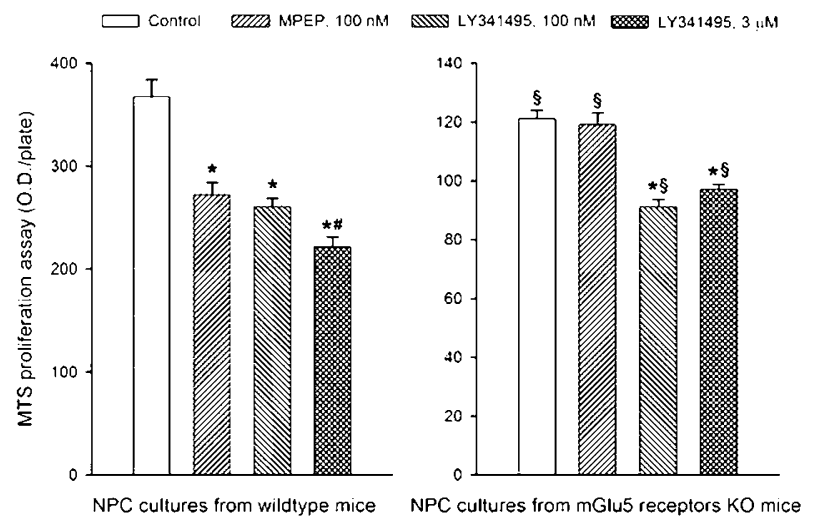

Figure 6 Cell proliferation in cultured NPCs prepared from wild-type or mGlu5 receptor knockout mice. Cell proliferation was assessed by the MTS assay after 4 days of treatment with the indicated drugs. Values are expressed as optical density (OD)/plate and represent the means + S.E.M. of four determinations $P<0.05$ (one-way ANOVA + Dunnett's t-test) versus $\left({ }^{*}\right)$ the respective control groups; (\#) the 'wild-type groups treated with MPEP or with $100 \mathrm{nM} \mathrm{LY341495}$ and $(\S)$ the corresponding values of wild-type cultures

receptors is required for an optimal proliferation and survival of stem/progenitor cells in the adult forebrain. Infusion with LY341495 reduced the number of $\mathrm{BrdU}^{+}$cells in the DG and to a lesser extent also in the SVZ. However, this action was unaffected by coinfusion with the mGlu2/3 receptor agonist LY379268. When infused alone, LY379268 had no effect on the number of proliferating cells in the SVZ but, unexpectedly, it lowered cell number in the DG, thus mimicking the action of the antagonist LY341495 (Figure 7d and h).

\section{Discussion}

NPCs offer the promise of novel repair strategy in the injured CNS. Their unique characteristics are object of intense investigation aimed at identifying the mechanisms that allow their positive enrichment both in vitro and in vivo. We have examined whether these mechanisms involve $m$ Glu receptors because (i) the native environment of NPCs is rich in extracellular glutamate and (ii) mGlu receptors are widely implicated in the regulation of developmental plasticity (see Introduction). We have found that NPCs in culture express mGlu5 receptors coupled to their canonical transduction pathways, that is, the stimulation of PI hydrolysis and MAP kinase activation. ${ }^{18,26-29}$ The use of MPEP and mGlu5 knockout mice showed that endogenous activation of mGlu5 receptors supports the proliferation and survival of NPCs in cultures, as well as in zones of active neurogenesis of the adult brain. This is a relevant finding because it discloses a novel aspect in the biology of NPCs. Interestingly, mGlu5 is the only mGlu receptor subtype detectable in large amounts in the embryonic life, and is expressed by endogenous NPCs in the developing and adult brain. ${ }^{30}$ The lower number of proliferating cells found in the DG and SVZ of mGlu5 knockout mice in spite of a normal brain morphology suggests that compensatory mechanisms might have occurred in these animals. However, it is noteworthy that mGlu5 knockout mice show behavioral abnormalities that may be consistent with a reduced proliferation of endogenous NPCs, including deficits in sensory-motor gating ${ }^{31}$ and spatial learning. ${ }^{32}$

Addition of mGlu5 receptor agonists to cultured NPCs supported cell proliferation in spite of the high concentrations of extracellular glutamate, indicating that the receptor was not 

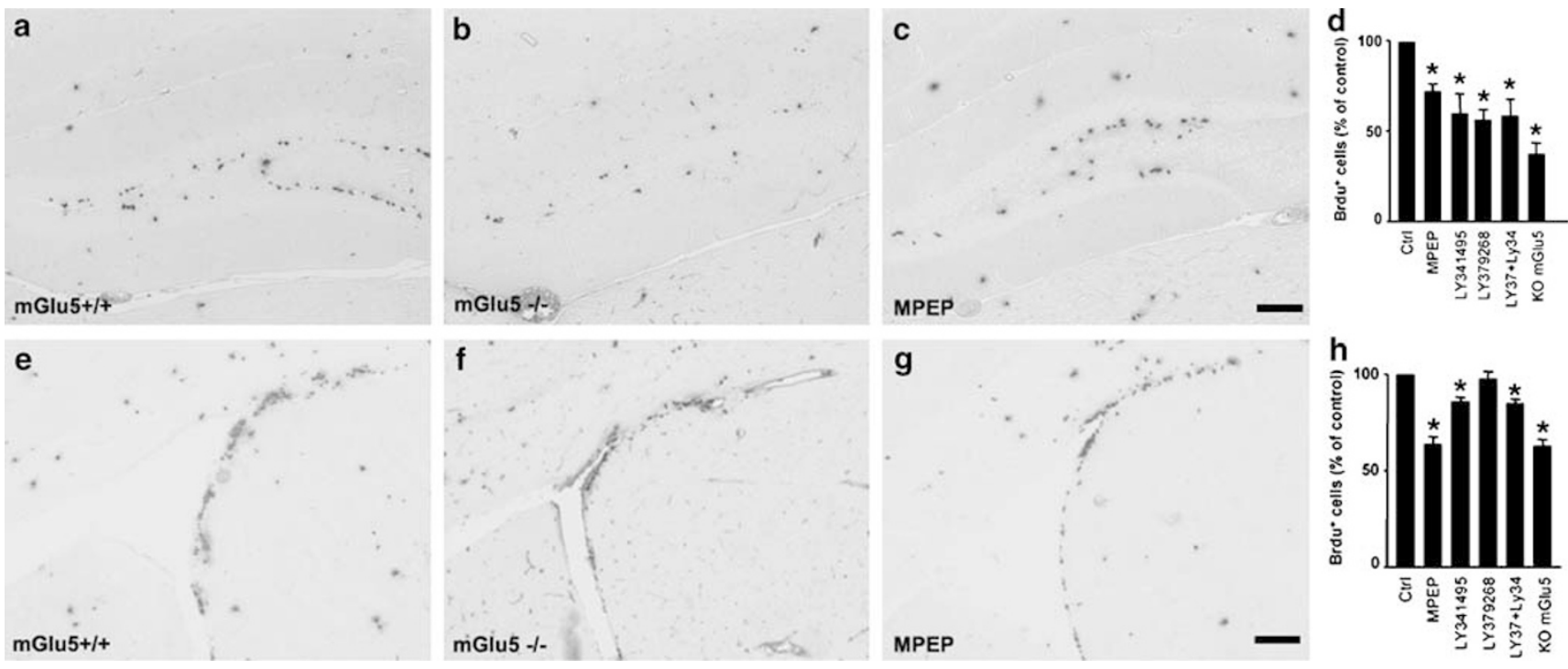

Figure 7 Proliferation of progenitor cells in zones of active neurogenesis of the adult mouse forebrain is under the control of mGlu receptors. Proliferating cells were identified by BrdU immunostaining in the DG (a-d) and SVZ (e-h). Note the smaller ventricular cavity in mGlu5 knockout mice (f). Values are means \pm S.E.M. of 4-6 determinations. ${ }^{*} P<0.05$ versus controls (Ctrl) (one-way ANOVA + Dunnett's $t$-test)

endogenously saturated. The large induction of all cyclins observed in response to a 3-day treatment with quisqualate was unexpected because cells had not been arrested and were exposed to mitogens (EGF and bFGF) since the time of plating. One possible explanation is that activation of mGlu5 receptors synchronizes groups of NPCs to proliferate. This process may involve the release of calcium from intracellular stores and the generation of intercellular calcium waves, as shown in cultured astrocytes challenged with glutamate. ${ }^{33-35}$ This 'synchronizing' activity of mGlu5 receptors might contribute to explain the heterogenous response of NPC cultures to MPEP or high concentrations of LY341495, as revealed by a distribution pattern of neurosphere diameters with multiple peaks (see Figure 5). Activation of mGlu5 receptors could also support NPC proliferation by stimulating the MAPK pathway, similarly to that observed for muscarinic $^{36,37}$ or opioid ${ }^{38}$ receptor activation. We conclude that mGlu5 receptors act as physiological regulators of NPC proliferation, and that mGlu5 receptor agonists may facilitate the expansion of NPCs in culture. The use of these drugs in vivo is limited by their toxicity and their poor brain penetration. The use of positive allosteric modulators of mGlu5 receptors may help to overcome these limitations. ${ }^{39}$

The role of mGlu3 receptors in the regulation of NPC proliferation and survival is less clear. In culture, selective blockade of these receptors with nanomolar concentrations of LY $341495^{25}$ reduced NPC proliferation and survival. These concentrations were also effective in cultures from mGlu5 knockout mice, suggesting that endogenous activation of mGlu3 receptors supports NPC proliferation independently of the presence of mGlu5 receptors. Treatment with LY379268, a potent mGlu2/3 receptor agonist, ${ }^{25}$ induced small changes in the expression of cyclin mRNA, and increased the percentage of neurospheres with large diameters. Results obtained in mice treated with mGlu2/3 receptor ligands are difficult to explain. A 7-day treatment with LY341495 reduced the number of proliferating NPCs in the SVZ and DG, but its action was not affected by the combined administration of LY379268. Whether this lack of competition is due to a different central bioavailability of the two drugs (due to a different brain penetration or peripheral metabolism) is unknown at present. Studies with multiple doses of LY379268 are needed to clarify this issue. LY379268 injected alone affected NPC number in the DG but not in the SVZ, which may simply reflect the different nature of dividing cells present in these two regions. ${ }^{40}$ Unexpectedly, treatment with LY379268 reduced the number of NPCs in the DG. This paradoxical effect might be related to the known ability of mGlu2/3 receptor agonists to reduce glutamate release in the $D G,{ }^{41}$ thus limiting the endogenous activation of mGlu receptors expressed by NPCs. On the other hand, we cannot exclude that, in in vivo studies, LY341495 might have recruited receptor subtypes other than mGlu2 or mGlu3, including the mGlu5 receptor itself. The use of mGlu3 knockout mice may help solve this caveat.

In conclusion, our results indicate that at least mGlu5 receptors are critically involved in the regulation of NPC proliferation and survival. A reduced proliferation of NPCs may limit the endogenous repair mechanisms when mGlu5 receptor antagonists are used as neuroprotective agents in neurodegenerative disorders. ${ }^{42,43}$

\section{Materials and Methods}

\section{Materials}

MPEP, quisqualate, DHPG and LY341495 were purchased from Tocris Cookson Ltd. (Bristol, UK). LY379268 was a generous gift from Eli Lilly Research Laboratories, Indianapolis, IN, USA. NBQX and all other chemicals were purchased from Sigma (Milano, Italy). 


\section{Cultures of NPCs}

NPCs were isolated from the forebrain of C57 black wild-type mice or from mGlu5 receptor knockout mice (purchased from Jackson Laboratories, Bar Harbor, ME, USA $)^{43}$ at embryonic day 20 (E20). Briefly, the brain tissue was collected in HBSS, mechanically dissociated to a single cell suspension and then resuspended in serum-free medium in the presence of 20 and $10 \mathrm{ng} / \mathrm{ml}$ of human recombinant EGF and bFGF, respectively. The cell suspension was plated at $500 \mathrm{cells} / \mathrm{cm}^{2}$ in untreated $25 \mathrm{~cm}^{2}$ tissue culture flasks (Nunc, USA) and made to grow as neurospheres. The proliferating medium is a DMEM-F12 optimized for neural progenitor cell growth (Euroclone, Irvine, Scotland) containing $0.6 \%$ glucose, $9.6 \mathrm{~g} / \mathrm{ml}$ putrescine, $6.3 \mathrm{ng} / \mathrm{ml}$ progesterone, $5.2 \mathrm{ng} / \mathrm{ml}$ sodium selenite, $0.025 \mathrm{mg} / \mathrm{ml}$ insulin and $0.1 \mathrm{mg} / \mathrm{ml}$ transferrin (sodium salt, grade II, Sigma). After 1 week, primary cultures were collected, mechanically dissociated and replated under the same conditions, in order to eliminate short-term dividing precursors. After dissociation, plated cells proliferate and give rise to secondary neurospheres. The cells were passaged every 5 days in the serum-free medium. The cells obtained as described above were immunopositive for nestin when grown as neurospheres, with less than 3\% of cells expressing GFAP or Tuj 1 . Moreover, when grown in $5 \%$ of serum and after removal of mitogens, they were able, after 1 week, to differentiate into neurons ( $5 \%$, as assessed by immunostaining for Tuj 1 ), astrocytes (80-90\%, as assessed by GFAP immunostaining) and oligodendrocytes (3-4\%, as assessed by GalC immunoreactivity).

At the time of the experiment (passages 4 or 12-14), cells were plated in suspension in serum-free medium onto $35 \mathrm{~mm}$ Nunc Petri dishes at the initial density of $0.5 \times 10^{6}$ cells/dish, and cultured for 4 days for the assessment of proliferation or survival. Drugs were applied daily for 3 days since the time of plating. Each treatment was run in triplicate. Images of cell cultures at different days of treatment were collected by a digital camera and the diameter of neurospheres was measured for each experimental condition.

\section{Immunocytochemistry}

In order to perform the staining in undifferentiated NPCs, the cells were plated on round coverslips and then centrifuged to make the spheres adherent. To stain the differentiated NPCs, the cells were plated in coated round coverslips, and differentiated with serum-containing medium for 10 days. Cultured NPCs (differentiated and undifferentiated) were fixed with $4 \%$ paraphormaldehyde for $15 \mathrm{~min}$. Following incubation with $4 \%$ of normal goat serum in TBS for $1 \mathrm{~h}$, the primary antibodies (Tuj1, Covance; GFAP, Sigma; GalC, Boehringer-Mannheim) were applied alone or in combination with the anti-nestin antibody (Chemicon) at $4^{\circ} \mathrm{C}$ overnight. Cells were then washed three times and FITC- or TRITC-conjugated secondary antibodies (anti-mouse for Tuj1, GFAP and GalC; anti-rabbit for nestin) were applied for $1 \mathrm{~h}$ at room temperature in order to visualize the labelled sites. Fluorescence was detected by a Zeiss laser scanner microscope (LSM510, Oberkochen, Germany).

\section{RT-PCR analysis}

RT-PCR analysis of mGlu receptors was performed as described previously. ${ }^{44}$ The following primers were used for each metabotropic glutamate receptor subtype indicated below: mGlu1: forward GCTGTA CCTACTATGCCTTC, reverse AGACCATGACACAGACTTGC; mGlu2: forward CTACAGTGATGTCTCCATCC, reverse AAAGCCTCAATGCCT GTCTC; mGlu3: forward CAAGTGACTACAGAGTGCAG, reverse CTGTC ACCAATGCTCAGCCTC; mGlu4: forward CCAACGAGGATGACATCA GG, reverse CACAGGTCACGGTGCATGG; mGlu5: forward GTCCTTCT
GTTGATCCTGTC, reverse ATGCAGCATGGCCTCCACTC; mGlu6: forward GCCAGTCAGATGATTCCACC, reverse GCCTGGTACCTGGAA GATGTC; mGlu7: forward CCAGATGTGGCAGTGTGTTC, reverse CGA GTCTTGATGGCATACAC; mGlu8: forward ATCACCTTCAGCCTCATC TC, reverse TGTGACCACAGCCTTGAAGC.

For $\beta$-actin amplification, we used the primers described by Roelen et al., ${ }^{45}$ which span an intron and yield products of different sizes depending on whether CDNA or genomic DNA is used as a template (400 and $600 \mathrm{bp}$, respectively).

\section{Western blot analysis}

Western blot analysis of mGlu receptor proteins was carried out as described previously ${ }^{44}$ using polyclonal antibodies against mGlu1a, mGlu4, mGlu5, mGlu6, mGlu7, mGlu8 (Upstate Technology) and mGlu2/3 (Chemicon International, Temecula, CA, USA) receptors. For the detection of phosphorylated or unphosphorylated forms of ERK-1, ERK2 or Akt, cultured NPCs were deprived of growth factors for $4 \mathrm{~h}$ and incubated with mGlu receptor ligands for $15 \mathrm{~min}$. The following primary antibodies were used: anti-phosphorylated ERK-1 and ERK-2 (monoclonal, $1: 2000$ ), anti-phosphorylated Akt (polyclonal, $1: 1000$ ) or anti-Akt (polyclonal, $1: 1000)$ (purchased from Cell Signaling Technology, Beverly, MA, USA), anti-ERK-1 and anti-ERK-2 (polyclonal, 1:2000) (from Santa Cruz Biotechnology, CA, USA).

\section{Measurement of PI hydrolysis}

For the stimulation of $\mathrm{PI}$ hydrolysis, cells were incubated overnight with $3 \mu \mathrm{Ci} /$ well myo[2- $\left.{ }^{3} \mathrm{H}\right]$ inositol (Amersham, specific activity $10 \mathrm{Ci} / \mathrm{mmol}$ ) to label inositol phospholipids. At the end of this incubation, cells were washed twice in Krebs-Henseleit buffer ( $\mathrm{pH}$ 7.4) containing $10 \mathrm{mM} \mathrm{Li}^{+}$ (added as LiCl). Cultures were stimulated with mGlu receptor agonists for $30 \mathrm{~min}$. The reaction was terminated by addition of methanol:chloroform: water $(1: 1: 1)$. The amount of $\left[{ }^{3} \mathrm{H}\right]$ inositol phosphates accumulating during the reaction was measured as described previously. ${ }^{6}$

\section{Measurement of intracellular cyclic AMP levels}

Cells were incubated in Krebs-Henseleit buffer containing $0.5 \mathrm{mM}$ isobutylmethylxanthine (IBMX) for $15 \mathrm{~min}$ at $37^{\circ} \mathrm{C}$ under constant oxygenation. After addition of forskolin and/or mGlu receptor ligands, the incubation was continued for a further $20 \mathrm{~min}$. The reaction was terminated by addition of an equal volume of ice-cold $0.8 \mathrm{~N} \mathrm{HClO}_{4}$. Samples were sonicated and centrifuged at low speed. The supernatants were added to $\mathrm{K}_{2} \mathrm{CO}_{3}$ and used for the assessment of CAMP by RIA (Amersham).

\section{Cell cycle analysis}

FACS analysis of cell cycle and DNA ploidy was carried out using a Coulter Elite flow cytometer after staining with propidium iodide $(50 \mu \mathrm{g} / \mathrm{ml})$ and treatment for $1 \mathrm{~h}$ with RNAse $(100 \mu \mathrm{g} / \mathrm{ml})$, as described previously. ${ }^{46}$ The transcripts of all cyclins involved in the regulation of the cell cycle were measured by RNAse protection assay (RPA) (BD Riboquant ${ }^{\mathrm{TM}}$ Multi-Probe Rnase Protection Assay System, mCYC-1).

\section{Assessment of cell proliferation}

Cell proliferation was evaluated by using the CellTiter 96 Aqueous One Solution Cell Proliferation Assay (Promega) according to the 
manufacturer's protocol. The assay is based on reduction of MTS to a colored formazan product, which is measured spectrophotometrically. Cells

were plated in 96-well plates in triplicate and were treated with mGlu receptor ligands each day for 3 days. At the end of the treatment, cells were incubated at $37^{\circ} \mathrm{C}$ in a $5 \% \mathrm{CO}_{2}$ incubator. Metabolically active cells were detected by adding $2 \mu \mathrm{l}$ of MTS to each well. After $2 \mathrm{~h}$ of incubation, the plates were red on a Multilabel Counter (Victor2; PerkinElmer).

\section{Assessment of cell death}

Cell death was assessed by measuring: (i) the percentage of cells bearing hypoploid DNA (see the Cell cycle analysis section; (ii) LDH release using a commercial kit (Roche Diagnostics Sp A, Milan, Italy); and (iii) caspase-3 activity using the Apo-ONE Homogenous caspase 3-7 assay kit (Promega, Madison, WI, USA). Caspase mRNA levels were measured by RNAse Protection Assay (BD Riboquant ${ }^{\mathrm{TM}}$ Multi-Probe Rnase Protection Assay System, mAPO-1).

\section{In vivo experiments}

Male C57/6N black mice (Charles River, Calco, Italy) were treated for 7 days with saline, MPEP, LY379268, LY341495 or LY341495 + LY379268 by means of subcutaneously implanted osmotic minipumps (Alzet) containing $100 \mu \mathrm{l}$ of a $200 \mathrm{mM}$ solution of each drug. Minipumps release $500 \mathrm{nl} / \mathrm{h}$ corresponding to a cumulative dose of $1 \mathrm{mg} / \mathrm{kg} /$ day of the drugs. All mice were treated with BrdU ( $50 \mathrm{mg} / \mathrm{kg}$, i.p., injected two times daily for 4 days) since the beginning of the drug treatment. Experiments were also carried out in mGlu5 receptor knockout mice and their controls. C57 black mice heterozygous for mGlu5 receptor gene deletion, obtained from The Jackson Laboratories (Bar Harbor, ME, USA), were bred to homozygosity. Homozygous females and males were fertile, but poor breeders. Thus, all mice were generated by heterozygous breeding. Mice were kept under environmentally controlled conditions $\left(22^{\circ} \mathrm{C}\right.$ with $40 \%$ humidity) on a $12-\mathrm{h}$ light/dark cycle with food and water ad libitum. Mice were identified by PCR analysis on tail samples after birth. The absence of mGlu5 receptors was then confirmed by Western blot analysis carried out in the olfactory bulbs when the brain was removed for the detection of $\mathrm{BrdU}^{+}$cells $(7$ days after the first injection of BrdU). Experiments were performed following the Guidelines for Animal Care and Use of the National Institutes of Health.

\section{BrdU immunohistochemistry}

Mice brains were removed and fixed in $4 \%$ paraformaldehyde/PBS for 2 days at $4{ }^{\circ} \mathrm{C}$ and then cryoprotected in 30\% sucrose for 3-7 days. Sagittal and coronal sections (10 $\mu \mathrm{m}$ thick) were cut at the cryostat and serially attached to gelatin-coated slices. Sections obtained as described above were permeabilized with $1 \mathrm{~N} \mathrm{HCl}$ solution and then incubated with $\mathrm{Na}_{2} \mathrm{~B}_{2} \mathrm{O}_{4}(100 \mathrm{mM})$. Slides were permeabilized for $30 \mathrm{~min}$ in TBS containing $0.2 \%$ Triton $X-100$. This was followed by preincubation in TBS containing $4 \%$ NGS for $30 \mathrm{~min}$. Sections were incubated overnight at $4{ }^{\circ} \mathrm{C}$ in primary monoclonal antibody against BrdU (Becton Dickinson). After PBS rinsing, the slices were incubated with the secondary antimouse biotinylated antibody (Vector Labs) and subsequently with $A B C$ solution (Vector Labs). Staining was developed using the DAB substrate kit for peroxidase (Vector Labs). Finally, sections were rinsed in TBS, dehydrated in increasing concentrations of ethanol, clarified and mounted on coverslips in a xylene-based mounting medium. Sections were viewed and photomicrographs were taken using an Olympus IX 50 microscope equipped with a Spot camera (Spot RT camera from Diagnostic Instruments Inc., Houston, TX).

\section{Acknowledgements}

This work is dedicated to the memory of Dr. Stefano Pagano and was supported by the Telethon Grant 1238.

\section{References}

1. Gage FH, Ray J and Fisher LJ (1995) Isolation, characterization, and use of stem cells from the CNS. Annu. Rev. Neurosci. 18: 159-192

2. Gritti A, Parati EA, Cova L, Frolichshal P, Galli R, Wanke E, Faravelli L, Morassutti DJ, Roisen F, Nickel DD and Vescovi AL (1996) Multipotential stem cells from the adult mouse brain proliferate and self-renew in response to basic fibroblast growth factor. J. Neurosci. 16: 1091-1100

3. McKay R (1997) Stem cells in the central nervous system. Science 276: 66-71

4. Pagano SF, Impagnatiello F, Girelli M, Cova L, Grioni E, Onofri M, Cavallaro M, Etteri S, Vitello F, Giombini S, Solero CL and Parati EA (2000) Isolation and characterization of neural progenitor cells from the adult human olfactory bulb. Stem Cells 18: 295-300

5. Reynolds BA and Weiss S (1992) Generation of neurons and astrocytes from isolated cells of the adult mammalian central nervous system. Science 255 : $1707-1710$

6. Nicoletti F, ladarola MJ, Wroblewski JT and Costa E (1986) Excitatory amino acid recognition sites coupled with inositol phospholipid metabolism: developmental changes and interaction with alpha1-adrenoceptors. Proc. Natl. Acad. Sci. USA 83: 1931-1935

7. Dudek SM and Bear MF (1989) A biochemical correlate of the critical period for synaptic modification in the visual cortex. Science 246: 673-675

8. Van den Pol AN, Romano C and Ghosh P (1995) Metabotropic glutamate receptor mGluR5 cellular distribution and developmental expression in the hypothalamus. J. Comp. Neurol. 362: 134-150

9. Romano C, Van den Pol AN and O'Malley KL (1996) Enhanced early developmental expression of the metabotropic glutamate receptor mGluR5 in rat brain: protein, mRNA splice variants, and regional distribution. J. Comp. Neurol. 367: 403-412

10. Casabona G, Knopfel T, Kuhn R, Gasparini F, Baumann P, Sortino MA, Copani $A$ and Nicoletti $F$ (1997) Expression and coupling to polyphosphoinositide hydrolysis of group I metabotropic glutamate receptors in early postnatal and adult rat brain. Eur. J. Neurosci. 9: 12-17

11. Huber KM, Sawtell NB and Bear MF (1998) Effects of the metabotropic glutamate receptor antagonist MCPG on phosphoinositide turnover and synaptic plasticity in visual cortex. J. Neurosci. 18: 1-9

12. Flint AC, Dammerman RS and Kriegstein AR (1999) Endogenous activation of metabotropic glutamate receptors in neocortical development causes neuronal calcium oscillations. Proc. Natl. Acad. Sci. USA 96: 12144-12149

13. Hannan AJ, Blakemore C, Katsnelson A, Vitalis T, Huber KM, Bear M, Roder J, Kim D, Shin HS and Kind PC (2001) PLC-beta1, activated via mGluRs, mediates activity-dependent differentiation in cerebral cortex. Nat. Neurosci. 4 282-288

14. Huber KM, Gallagher SM, Warren ST and Bear MF (2002) Altered synaptic plasticity in a mouse model of fragile $X$ mental retardation. Proc. Natl. Acad. Sci. USA 99: 7746-7750

15. Lopez-Bendito G, Shigemoto R, Fairen A and Lujan R (2002) Differential distribution of group I metabotropic glutamate receptors during rat cortical development. Cereb. Cortex 12: 625-638

16. Catania MV, Bellomo M, Di Giorgi Gerevini V, Seminara G, Giuffrida R, Romeo $R$, De Blasi A and Nicoletti $F$ (2001) Endogenous activation of group-I metabotropic glutamate receptors is required for differentiation and survival of cerebellar Purkinje cells. J. Neurosci. 21: 7664-7673

17. Pin J-P and Duvoisin R (1995) The metabotropic glutamate receptors: structure and functions. Neuropharmacology 34: 1-26 
18. De Blasi A, Conn PJ, Pin J-P and Nicoletti F (2001) Molecular determinants of metabotropic glutamate receptor signaling. Trends Pharmacol. Sci. 22 $114-120$

19. Heck S, Enz R, Richter-Landsberg $C$ and Blohm DH (1997) Expression of eight metabotropic glutamate receptor subtypes during neuronal differentiation of P19 embryocarcinoma cells: a study by RT-PCR and in situ hybridization. Brain Res. Dev. Brain Res. 101: 85-91

20. Zirpel L, Janowiak MA, Taylor DA and Parks TN (2000) Developmental changes in metabotropic glutamate receptor-mediated calcium homeostasis. J. Comp. Neurol. 421: 95-106

21. Skerry TM and Genever PG (2001) Glutamate signalling in non-neuronal tissues. Trends Pharmacol. Sci. 22: 174-181

22. Copani A, Casabona G, Bruno V, Caruso A, Condorelli DF, Messina A Di Giorgi Gerevini V, Pin JP, Kuhn R, Knopfel T and Nicoletti F (1998) The metabotropic glutamate receptor mGlu5 controls the onset of developmental apoptosis in cultured cerebellar neurons. Eur. J. Neurosci. 10: 2173-2184

23. Gasparini F, Lingenhohl K, Stoehr N, Flor PJ, Heinrich M, Vranesic I, Biollaz M, Allgeier H, Heckendorn R, Urwyler S, Varney MA, Johnson EC, Hess SD, Rao SP, Sacaan Al, Santori EM, Velicelebi G and Kuhn R (1999) 2-Methyl-6(phenylethynyl)-pyridine (MPEP), a potent, selective and systemically active mGlu5 receptor antagonist. Neuropharmacology 38: 1493-1503

24. Goudet C, Gaven F, Kniazeff J, Vol C, Liu J, Cohe-Gonsaud M, Acher F, Prezeau L and Pin J-P (2003) Heptahelical domain of metabotropic glutamate receptor 5 behaves like rhodopsin-like receptors. Proc. Natl. Acad. Sci. USA 101: 378-383

25. Schoepp DD, Jane DE and Monn JA (1999) Pharmacological agents acting at subtypes of metabotropic glutamate receptors. Neuropharmacology 38: $1431-1476$

26. Abe T, Sugihara H, Nawa H, Shigemoto R, Mizuno N and Nakanishi S (1992) Molecular characterization of a novel metabotropic glutamate receptor mGluR5 coupled to inositol phosphate/ $/ \mathrm{Ca}^{2+}$ signal transduction. J. Biol. Chem. 267: 13361-13368

27. Peavy RD and Conn PJ (1998) Phosphorylation of mitogen-activated protein kinase in cultured rat cortical glia by stimulation of metabotropic glutamate receptors. J. Neurochem. 71: 603-612

28. Peavy RD, Sorensen SD and Conn PJ (2002) Differential regulation of metabotropic glutamate receptor 5-mediated phosphoinositide hydrolysis and extracellular signal-regulated kinase responses by protein kinase $\mathrm{C}$ in cultured astrocytes. J. Neurochem. 83: 110-118

29. Thandi S, Blank JL and Challis RA (2002) Group-I metabotropic glutamate receptors, mGlu1a and mGlu5a, couple to extracellular signal-regulated kinase (ERK) activation via distinct, but overlapping, signalling pathways. J. Neurochem. 83: 1139-1153

30. Di Giorgi Gerevini VD, Caruso A, Cappuccio I, Ricci Vitiani L, Romeo S, della Rocca C, Gradini R, Melchiorri D and Nicoletti F (2004) The mGlu5 metabotropic glutamate receptor is expressed in zones of active neurogenesis of the embryonic and postnatal brain. Dev. Brain. Res. 150: 17-22

31. Kinney GG, Burno M, Campbell UC, Hernandez LM, Rodriguez D, Bristow LJ and Conn PJ (2003) Metabotropic glutamate subtype 5 receptors modulate locomotor activity and sensorimotor gating in rodents. J. Pharmacol. Exp. Ther. 306: 116-123
32. Lu YM, Jia Z, Janus C, Henderson JT, Gerlai R, Wojtowicz JR and Roder JC (1997) Mice lacking metabotropic glutamate receptor 5 show impaired learning and reduced CA1 long-term potentiation (LTP) but normal CA3 LTP. J. Neurosci. 17: 5196-5205

33. Kim WT, Rioult MG and Cornell-Bell AH (1994) Glutamate-induced calcium signaling in astrocytes. Glia 11: 173-184

34. Nakahara K, Okada M and Nakanishi S (1997) The metabotropic glutamate receptor mGluR5 induces calcium oscillations in cultured astrocytes via protein kinase C phosphorylation. J. Neurochem. 69: 1467-1475

35. Ciccarelli R, Sureda FX, Casabona G, Di lorio P, Caruso A, Spinella F, Condorelli DF, Nicoletti $F$ and Caciagli $F$ (1997) Opposite influence of the metabotropic glutamate receptor subtypes mGlu3 and -5 on astrocyte proliferation in culture. Glia 21: 390-398

36. Li B-S, Ma W, Zhang L, Barker JL, Stenger DA and Pant HC (2001) Activation of phosphatidylinositol-3-kinase (PI-3K) and extracellular regulated kinases (Erk1/2) is involved in muscarinic receptor-mediated DNA synthesis in neural progenitor cells. J. Neurosci. 21: 1569-1579

37. Zhao W-Q, Alkon D and Ma W (2003) C-Src protein tyrosine kinase activity is required for muscarinic receptor-mediated DNA synthesis in neurogenesis via ERK1/2 and CAMP-responsive element-binding protein signaling in neural precursor cells. J. Neurosci. Res. 72: 334-342

38. Persson Al, Thorlin T, Bull C and Eriksson PS (2003) Opioid-induced proliferation through the MAPK pathway in cultures of adult hippocampal progenitors. Mol. Cell Neurosci. 23: 360-372

39. O'Brien JA, Lemaire W, Chen TB, Chang RS, Jacobson MA, Ha SN, Lindsley CW, Schaffauser HJ, Sur C, Pettibone DJ, Conn PJ and Williams Jr DL (2003) A family of highly selective allosteric modulators of the metabotropic glutamate receptor subtype 5. Mol. Pharmacol. 64: 731-740

40. Seaber RM and van der Kooy D (2002) Adult rodent neurogenic regions: the ventricular subependyma contains neural stem cells, but the dentate gyrus contains restricted progenitors. J. Neurosci. 22: 1784-1793

41. Dietrich D, Kral T, Clusmann H, Friedl M and Schramm J (2002) Presynaptic group-II glutamate receptors reduce stimulated and spontaneous transmitter release in human dentate gyrus. Neuropharmacology 42: 297-305

42. Bruno V, Battaglia G, Copani A, D'Onofrio M, Di lorio P, De Blasi A, Melchiorri D, Flor PJ and Nicoletti F (2001) Metabotropic glutamate receptors as targets for neuroprotective drugs. J. Cereb. Blood Flow Metab. 21: 1013-1033

43. Battaglia G, Busceti CL, Molinari G, Biagioni F, Storto M, Fornai F, Nicoletti $F$ and Bruno V (2003) Endogenous activation of mGlu5 metabotropic glutamate receptors contributes to the development of nigro-striatal damage induced by 1-methyl-4-phenyl-1, 2, 3, 6-tetrahydropyridine in mice. J. Neurosci. 24: 828-835

44. Chiechio S, Caricasole A, Barletta E, Storto M, Catania MV, Copani A, Vertechy M, Nicolai R, Calvani M, Melchiorri D and Nicoletti F (2002) -Acetylcarnitine induces analgesia by selectively up-regulating mGlu2 metabotropic glutamate receptors. Mol. Pharmacol. 61: 989-996

45. Roelen BA, Lin HY, Knezevic V, Freunds E and Mummery CL (1994) Expression of TGF-beta and their receptors during implantation and organogenesis of the mouse embryo. Dev. Biol. 166: 716-728

46. Copani A, Condorelli F, Caruso A, Vancheri C, Sala A, Giuffrida Stella AM, Canonico PL, Nicoletti F and Sortino MA (1999) Mitotic signaling by betaamyloid causes neuronal death. FASEB J. 13: 2225-2234 